\title{
RECONSTRUCTIA DEFECTULUI DE DEGET FOLOSIND LAMBOUL INSULAR REVERS METACARPIAN DORSAL. CAZ CLINIC
}

\author{
Roatiş Marius Dinu' \\ ISpitalul Județean de Urgență Satu Mare, medic specialist chirurgie plastică microchirurgie reconstructivă \\ corespondență email:dr_mariusdinu@yahoo.com
}

\begin{abstract}
The reverse dorsal metacarpal flap provides an excellent and reliable method to cover skin defects over fingers. This flap has the advantage of a good quality of skin paddle matched up with the skin over the fingers. From 2006 to 2008, I performed 5 cases of reverse dorsal metacarpal flaps to cover skin defects over the second and third finger.

Key Words: reverse dorsal metacarpal flap, skin defect, finger.

Rezumat: Lamboul metacarpian dorsal reprezintă o metodă excelentă și sigură pentru acoperirea defectelor cutanate de la nivelul degetelor. Acest lambou are avantajul unui tegument de calitate care se potrivește cu pielea degetelor. În intervalul 2006-2008 am realizat cinci astfel de lambouri metacarpiene dorsale pentru a acoperi defecte cutanate de la nivelul degetelor 2 și 3.

Cuvinte cheie: lambou revers metacarpian dorsal, defect cutanat, deget.

Traumatismele de mână soldate cu defecte de tegument la nivelul degetelor și expunerea de tendoane, oase, sau articulații, pot reprezenta pentru chirurgul plastician o provocare atât din punct de vedere estetic cât și funcțional. Principiile de reconstrucție în această zonă sunt următoarele: închiderea rapidă a plăgii pentru a permite o mobilizare imediată a degetului utilizând rezervele cutanate locale ori de câte ori este posibil și evitarea unui aspect neplăcut sau deformant al zonei donatoare. Pentru repararea acestor defecte o mare diversitate de lambouri au fost descrise, multe dintre ele prezentând o serie de neajunsuri, cum ar fi necesitatea imobilizării degetului sau mâinii, limitarea arcului de rotație a lamboului, sau sacrificarea unei artere digitale. Tegumentul feței dorsale a degetului sau mâinii reprezintă o excelentă zonă donatoare. Lamboul metacarpian dorsal revers este o alternativă optimă pentru acoperirea defectelor cutanate de la nivelul degetelor și a fost descris în 1990 de Lu și Wan în China și Maruyama și Quaba în literatura se specialitate engleză.
\end{abstract}

\section{Anatomie}

Arterele metacarpiene dorsale (AMD) (a doua, a treia și a patra) sunt artere constante care coboară între tendoanele extensorii și mușchii interosoși, de obicei în spațiul dintre două metacarpiene vecine (Fig.1). Originea AMD este în arcul arterial palmar profund și rețeaua arterială dorsală a pumnului, care include arcul arterial metacarpian bazal, intercarpian și radiocarpian.

Arcada arterială palmară profundă trimite 3 perforante dorsale prin spațiul intermetacarpian proximal pentru a forma AMD și reprezintă sursa principală pentru AMD. Simultan fiecare AMD comunică cu rețeaua arterială a pumnului. În apropierea spaţiului comisural AMD se anastomozează cu artera digitală comună sau proprie (Fig.4), această anastomoză stând la baza lamboului metacarpian revers. Fiecare AMD este însoțită de două vene comitante, care asigură drenajul venos al lamboului. 


\section{CAZURI CLINICE}

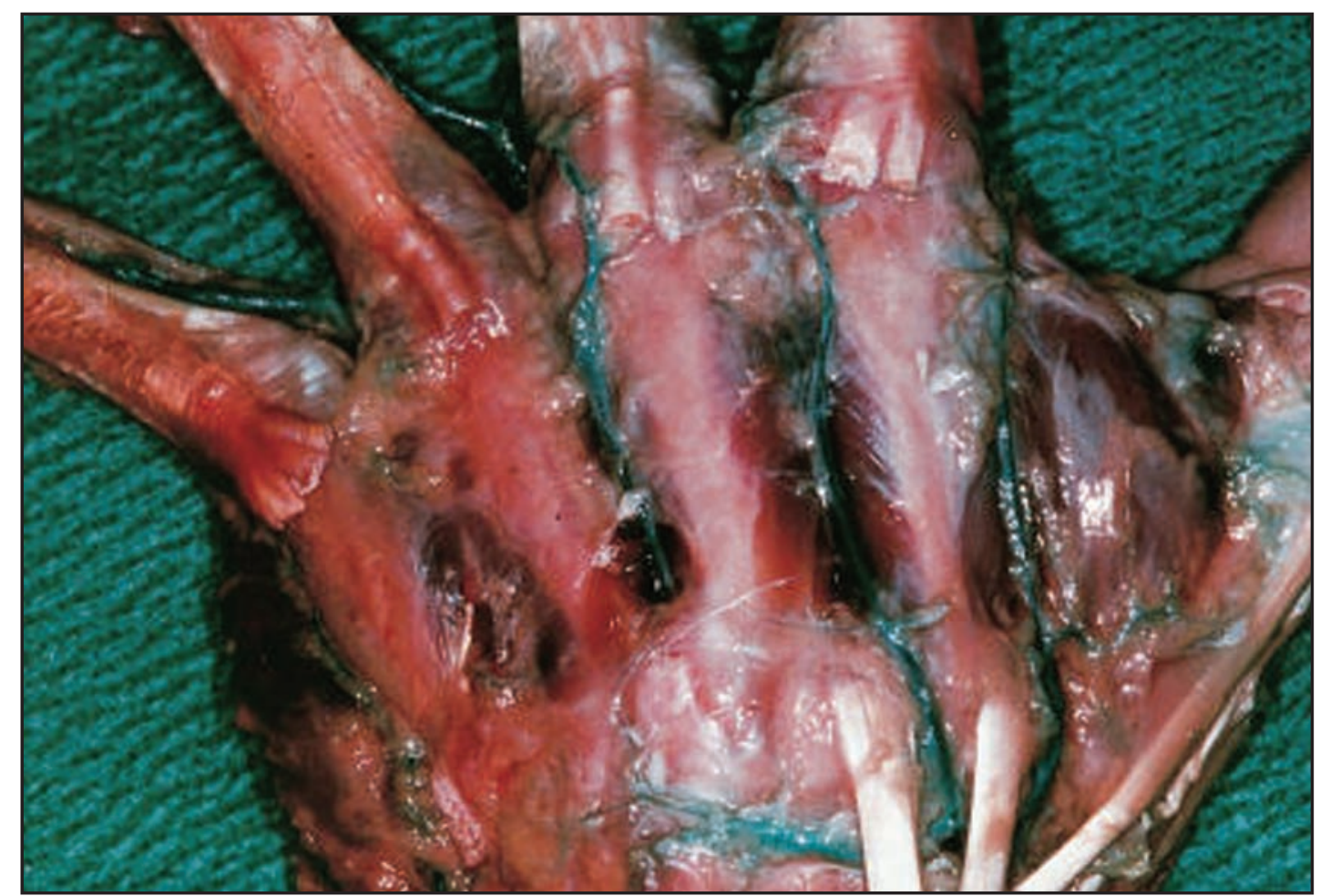

Fig.1 Arterele metacarpiene dorsale după colorație prin injectare cu albastu de metilen

(Anatomie der dorsalen Mittelhandarterien-Anatomische Untersuchung und Literaturübersicht Handchir Mikrochir Plast Chir 2001; 33:77-82)

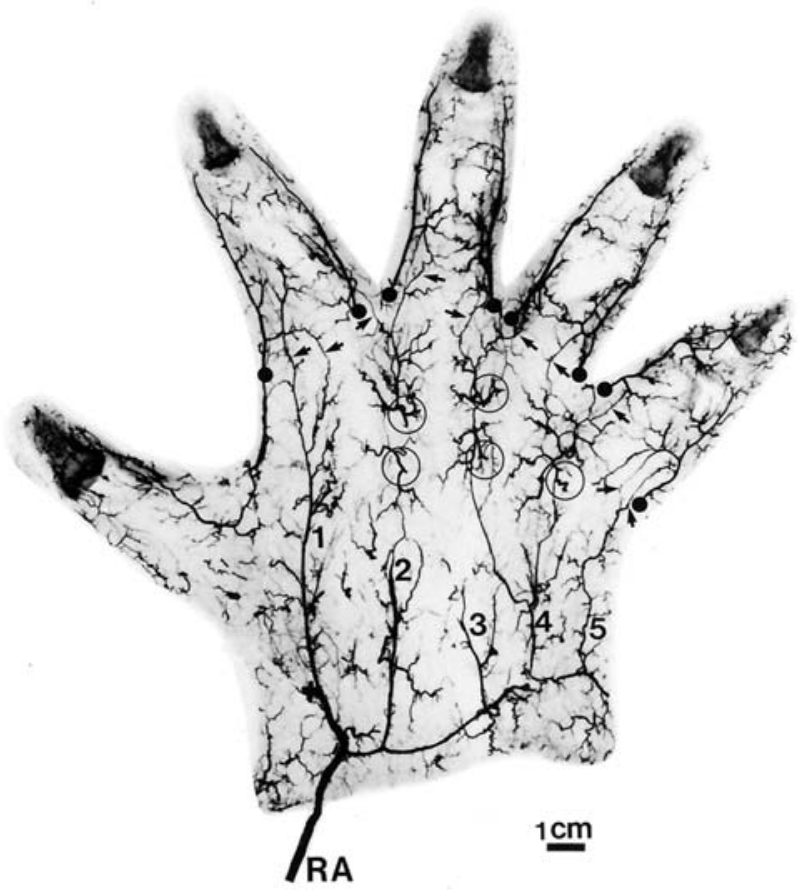

Fig.2 Angiografia dorsala a mâinii

RA: artera radială; 1,2,3,4: arterele metacarpiene dorsale; Punctele negre: arterele digitale palmare; Cercurile: perforantele dorsale din arterele metacarpiene palmare; Săgețile mici: anastomozele vasculare între ramurile cutanate dorsale proximale din arterele digitale palmare şi ramurile digitale dorsale din arterele metacarpiene dorsale (Reversed Dorsal Digital and Metacarpal Island Flaps Supplied by the Dorsal Cutaneous Branches of the Palmar Digital Artery. Yang D,

Steven F. Morris, Annals of Plastic Surgery 2001; 4(46))

Lambourile metacarpiene dorsale pe flux revers au fost studiate amănunțit. Angiograma (fig.2) arată că prima arteră metacarpiană dorsală ia naștere constant din artera radială, iar a doua, a treia și a patra, de obicei din arcul arterial carpian dorsal. 


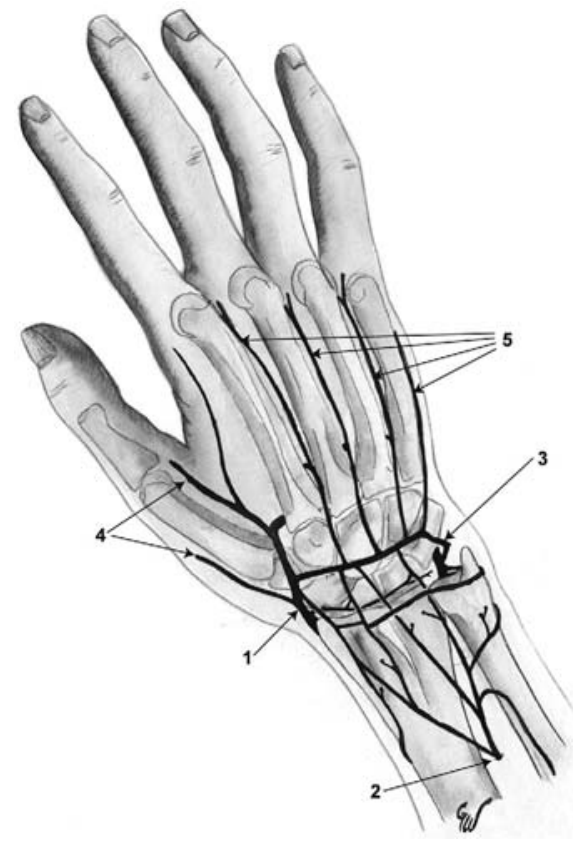

Fig.4

1. artera metacarpiană dorsală

2. artera digitală proprie

3. anastomoza dintre artera metacarpiană dorsală şi artera metacarpiană palmară

4. anastomoza dintre rețeaua arterială dorsală şi artera digitală proprie (A New Approach to the Reverse Dorsal Metacarpal Artery Flap, Karacalar A, Dzcan M, The Journal of Hand Surgery)

\section{Tehnică operatorie}

Operația s-a efectuat în anestezie locoregională și anume un bloc la nivelul pumnului cu xilină $1 \%$ sub bandă tourniquet fără exanghinare. Pe baza defectului rezultat în urma debridării chirurgicale am ales AMD, apoi am croit lamboul luând ca ax mijlocul spațiului dintre cele două metacarpiene (fig.5). Planul de disecție a insulei cutanate a fost între fascie și paratenonul extensorilor, iar a pediculului vascular sub epimisiumul interosoșilor dorsali.

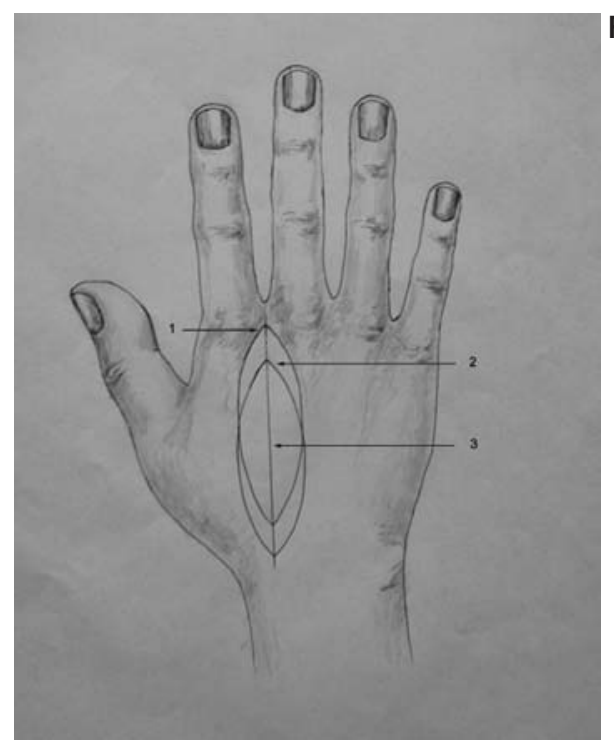

Fig.5. Schița lamboului (Lai-Jin et al. Annals of Plastic Surgery 2008;4(61)) 


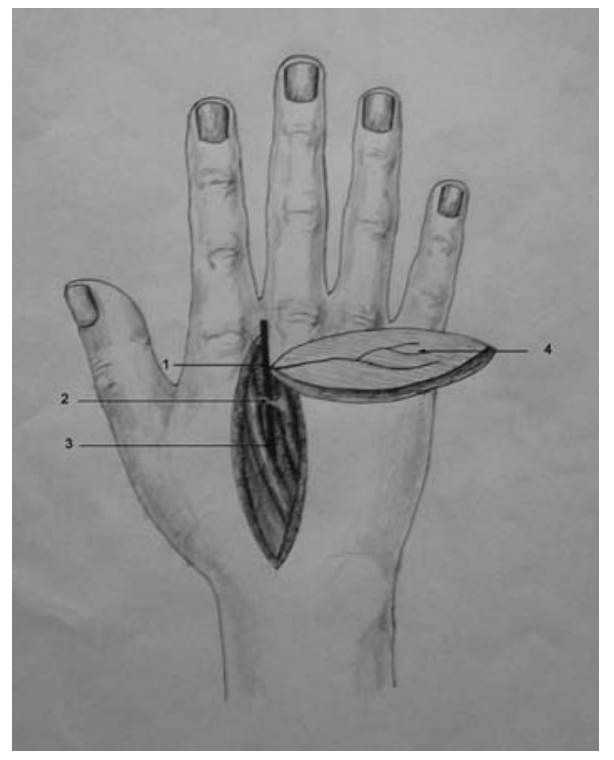

Fig.6 Ridicarea lamboului (Lai-Jin et al. Annals of Plastic Surgery 2008; $4(61))$

\section{Caz clinic}

Pacient în vîrstă de 38 ani, se adresează Serviciului de Chirurgie Plastică a Spitalului Județean de Urgență Satu Mare cu un defect de părți moi pe fața dorsolaterală a falangei proximale și fața laterală a falangei medii a indexului drept, cu interesarea parțială a aparatului extensor până la falanga osoasă, ca urmare a unei infecții cronice posttraumatice. Acest pacient suferise anterior cu 4 săptămâni un traumatism la circular, când s-a adresat de urgență unui spital municipal, unde s-a practicat toaleta chimică și chirurgicală, urmată de sutură în tensiune. Evoluția a fost nefavorabilă, cu infecție, necroză suplimentară și apariția defectului sus-amintit (Fig.7,8).

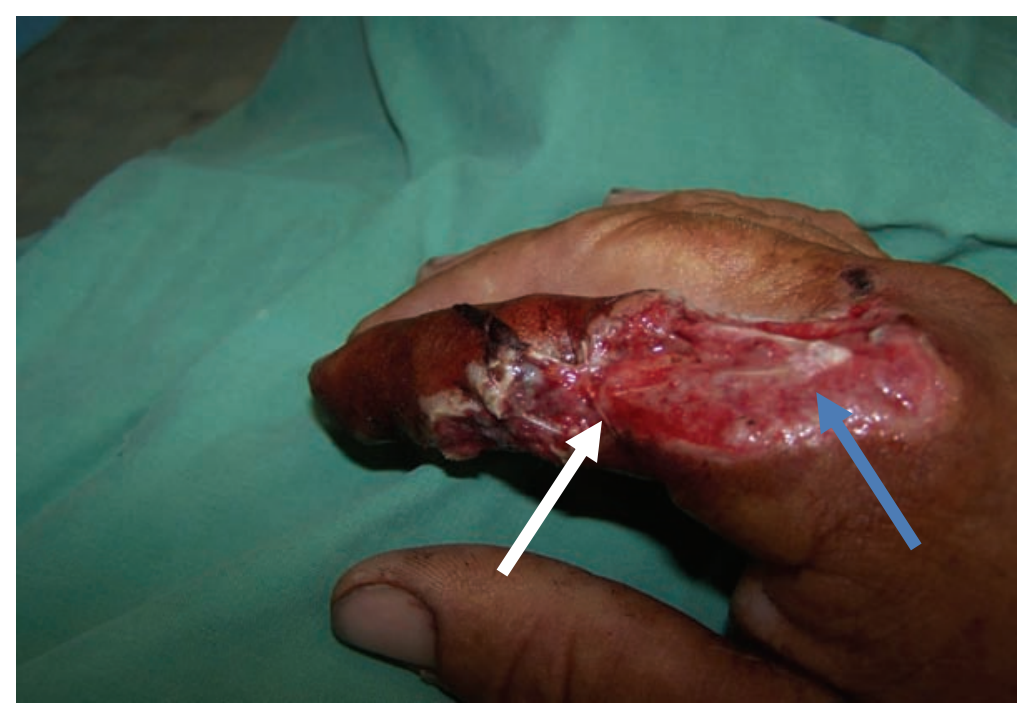

Fig.7 Defectul de tegument la nivelul indexului drept, vedere laterală (săgeata albă indică fir de sutură, iar săgeata albastră indică suprafață osoasă denudată) 


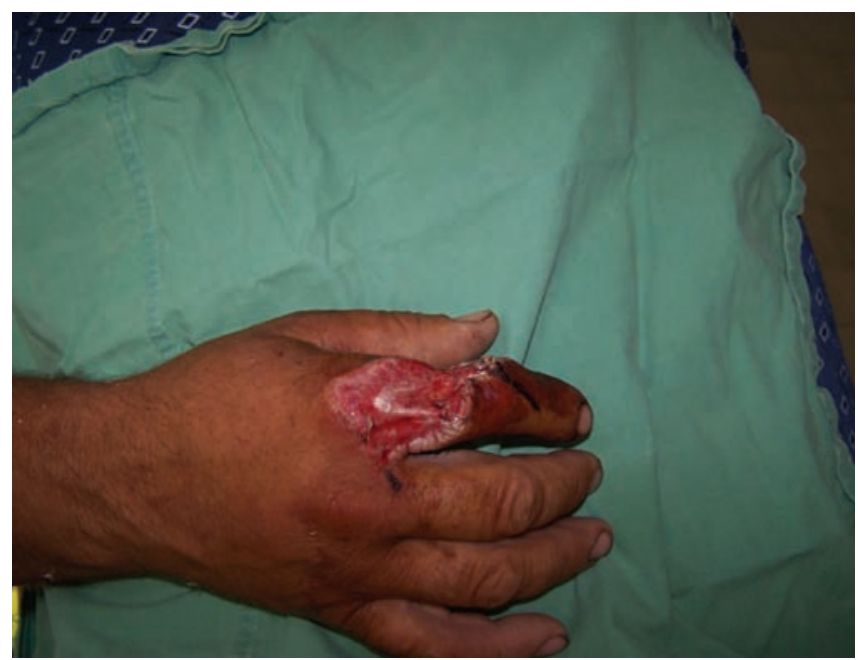

Fig.8 Acelaşi caz, vedere de sus

După excizia largă a țesuturilor devitalizate și toaleta chimică corespunzătoare, s-a croit un lambou insular fasciocutanat metacarpian dorsal revers, bazat pe a doua arteră metacarpiană dorsală (Fig.9).

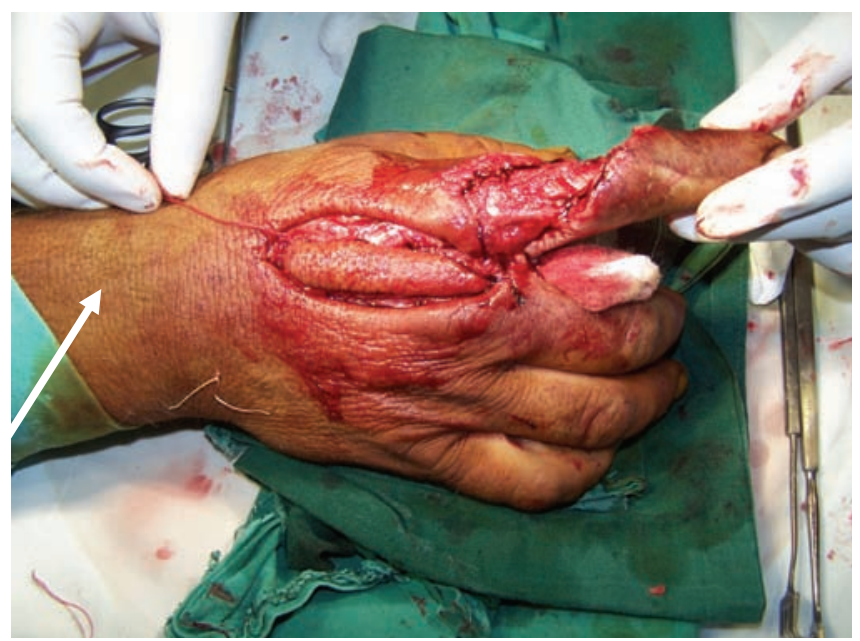

Fig.9 Ridicarea lamboului metacarpian dorsal (săgeata indică insula cutanată a lamboului)

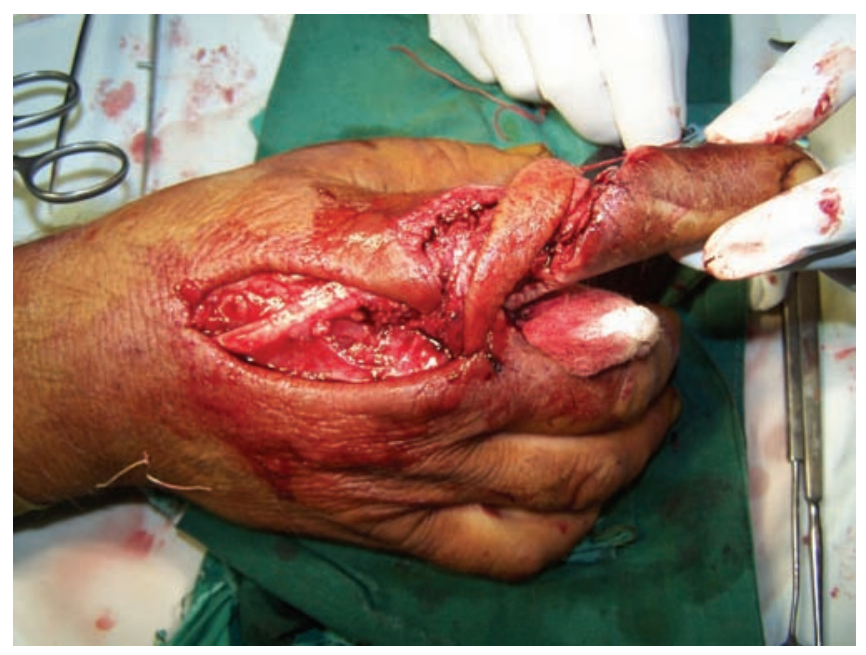

Fig 10 Transpoziția lamboului la nivelul defectului 


\section{CAZURI CLIJNICE}

Evoluția a fost excelentă, vindecarea s-a realizat rapid, fără nici un semn de suferință din partea lamboului, acesta integrându-se perfect și în totalitate. De asemenea rezultatul funcțional a fost foarte bun, cu un minim deficit de extensie de aproximativ 5 grade (Fig.11,12).

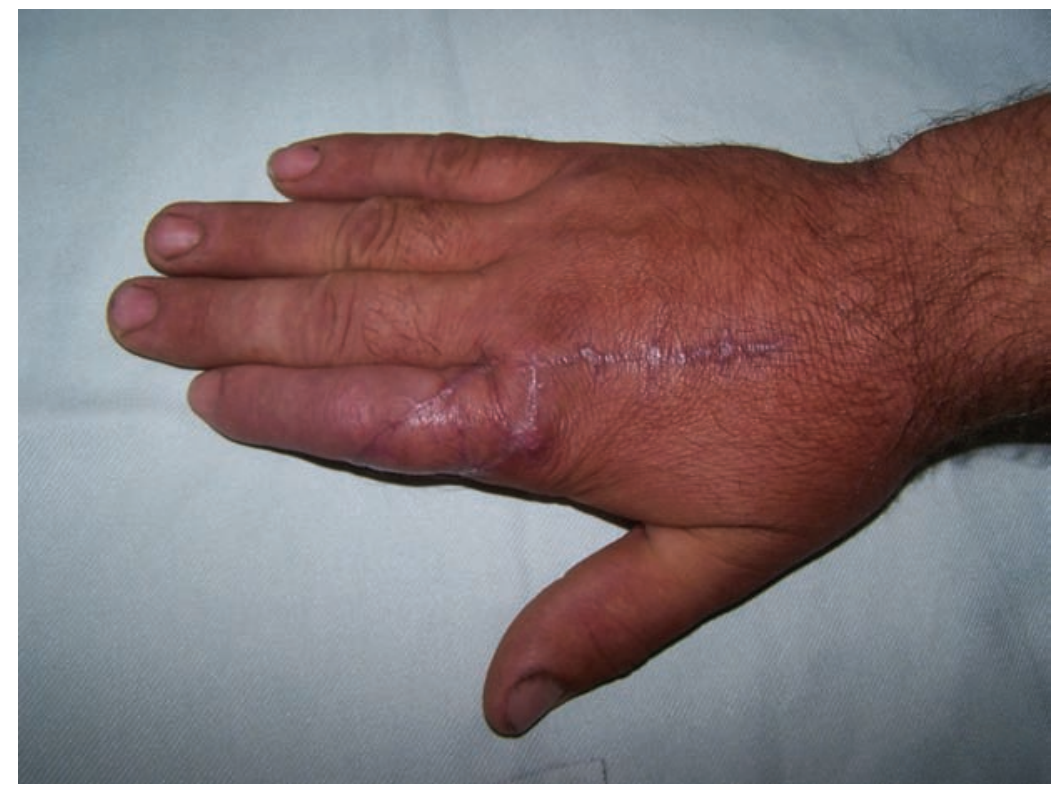

Fig. 11

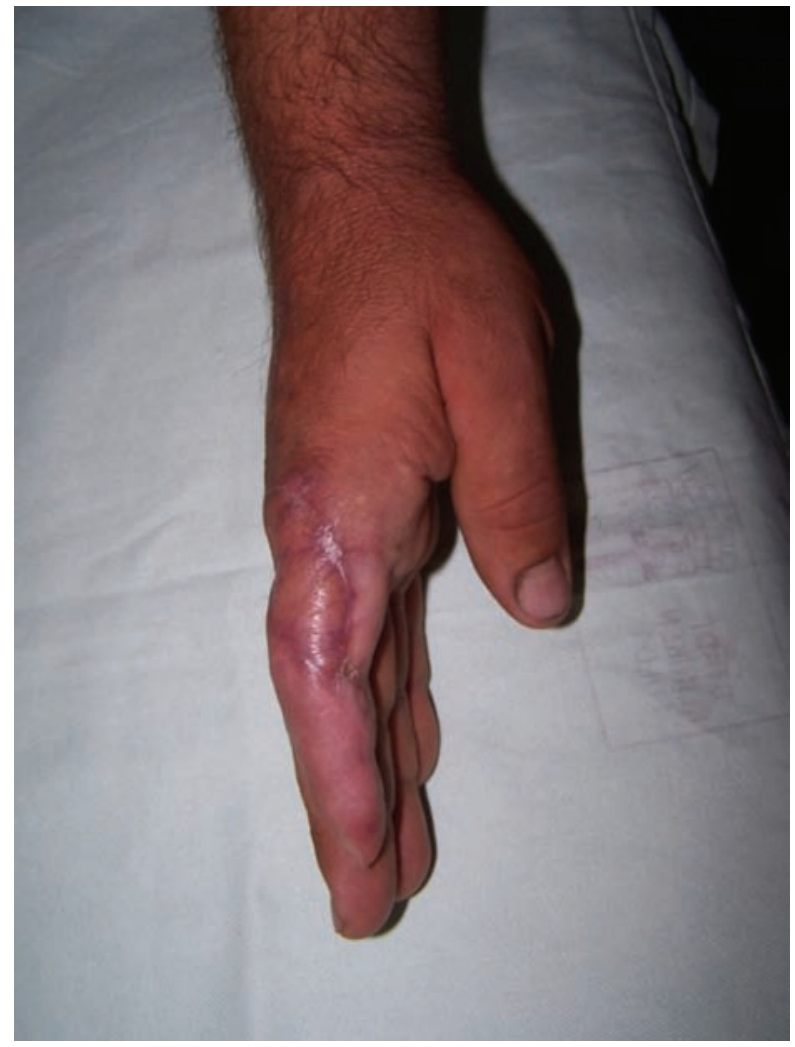

Fig. 12

Pe perioada 2006-2008 în Spitalul Județean Satu Mare am realizat 5 astfel de lambouri, toate având o evoluție foarte bună. 


\section{Discuții}

Au fost descrise în literatura de specialitate numeroase tehnici de reconstucție a defectelor cutanate ale mâinii. Cele mai noi concepte legate de lambourile intinseci ale mâinii au prins teren în acoperirea defectelor la acest nivel. Multe din aceste lambouri sunt găsite pe fața dorsolaterală a mâinii și degetelor, puține fiind recoltate de pe fața palmară. Utilizarea acestor lambouri permite o mobilizare activă precoce. Lambourile metacarpiene dorsale au câștigat în popularitate, iar rolul lor în reconstrucția mâinii este bine stabilit. Aceste lambouri asigură o reconstrucție într-o singură etapă, de o calitate excelentă, cu o vascularizație independentă care permite închiderea primară a zonei donatoare, fără a sacrifica o arteră importantă a mâinii. Cu toate aceste avantaje, acest tip de lambou prezintă unele inconveniente pe care însă le putem cataloga minore, și anume: necesită atenție și un timp puțin mai prelungit pentru recoltare, prezența firelor de păr la nivelul lamboului și a cicatricii pe fața dorsală a mâinii.

În concluzie, acest lambou metacarpian dorsal rămâne foarte util în reconstrucția defectelor la degete. Indicațiile sale merg de la defectele posttraumatice acute, cicatrici instabile, infecții cronice posttraumatice, până la boala Dupuytren.

\section{Referințe}

1. Lu Lai-Jin, Gong Xu, Cui Jian-Li, Sun Xi-Guang. A Modified Approach of the Reverse Dorsal Metacarpal Island Flap Anatomical Basis and Application in 24 Cases, Annals of Plastic Surgery 2008;4(61)

2. Gregory H, Heitmann C, Germann G. The evolution and refinements of the distally based dorsal metacarpal artery (DMCA) flaps, Journal of Plastic, Reconstructive \& Aesthetic Surgery 2007;60,73-739

3. Lu Lai-jin, Gong Xu. The Reverse Dorsal Metacarpal Flap Experience With 153 Cases Annals of Plastic Surgery 2006;6(56)

4. Marx A, Preisser P, Peek A, Partecke BD. Anatomie der dorsalen Mittelhandarterien-Anatomische Untersuchung und Literaturübersicht, Handchir Mikrochir Plast Chir 2001;33,77-82

5. Yang D, Morris SF. Vascular basis of dorsal digital and metacarpal skin flaps. J Hand Surg [Am] 2001;26A.142-146

6. Karamursel S, Celebioglu S. Reverse-Flow First Dorsal Metacarpal Artery Flap for Index Fingertip Reconstruction, Annals of Plastic Surgery 2005;6(54)

7. Fontaine C, Wavreille G, Chantelot C, Prodhomme G. Anatomie chirurgicale de la face dorsale de la main et du poignet, Chirurgie de la main 2005;24.64-78

8. Can Cedidi C, Schumacher O, Dabernig J, Ingianni G. The Compound Dorsal Metacarpal Artery Tendofasciocutaneous Flap An Attractive Reconstructive Tool for Complex Digital Defects, Annals of Plastic Surgery 2006;6(56)

9. Maruyama Y. The reverse dorsal metacarpal artery flap. Br J Plast Surg 1990;43:24-27

10. Quaba AA, Davison MP. The distally-based dorsal hand flap. Br J Plast Surg 1990;43:28-39

11. Dautel G, Merle M. Dorsal metacarpal reverse flaps: anatomical basis and clinical applications. J Hand Surg [Br] 1991;16B:400-405

12. Dautel G, Merle M. Direct and reverse dorsal metacarpal flaps. Br J Plast Surg 1992;45:123-130

13. Bene MD, Petrolati M, Raimondi P, et al. Reverse dorsal digital island flap. Plast Reconstr Surg 1994;93:552-557

14. Pelissier P, Casoli V, Bakhach J, et al. Reverse dorsal digital and metacarpal flaps: a review of 27 cases. Plast Reconstr Surg 1999;103:159-165 